Research Paper

\title{
Impact of Cryoballoon Ablation in Hypertrophic Cardiomyopathy-related Heart Failure due to Paroxysmal Atrial Fibrillation. A Comparative Case Series
}

\author{
Petra Maagh ${ }^{1 凶}$, Gunnar Plehn ${ }^{2,4}$, Arnd Christoph ${ }^{1}$, Ahmet Oernek ${ }^{3}$, Axel Meissner ${ }^{1,4}$ \\ 1. Department of Cardiology, Rhythmology and Internal Intensive Care, Klinikum Köln-Merheim, University Witten-Herdecke, Ostmerheimer Str. 200, 51109 \\ Cologne, Germany \\ 2. Department of Cardiology and Angiology, Johanniter-Krankenhaus Rheinhausen GmbH, Kreuzacker 1-7, 47228 Duisburg, Germany; \\ 3. Department of Diagnostic and Interventional Radiology, Berufsgenossenschaftliches Universitätsklinikum Bergmannsheil GmbH, Bürkle-de-la-Camp-Platz \\ 1, 44789 Bochum, Germany; \\ 4. Ruhr-University Bochum, Faculty of Medicine, Universitätsstraße 150, 448801 Bochum, Germany \\ $\triangle$ Corresponding author: Petra Maagh, Klinikum Köln-Merheim, University Witten/Herdecke/Germany, Ostmerheimer Str. 200, 51109 Cologne, Germany, \\ Tel.: 0049/221 8907-3457, Fax: 0049/221 8907-3488, e-mail: Petra.Maagh@rub.de
}

() Ivyspring International Publisher. Reproduction is permitted for personal, noncommercial use, provided that the article is in whole, unmodified, and properly cited. See http://ivyspring.com/terms for terms and conditions.

Received: 2016.05.16; Accepted: 2016.07.13; Published: 2016.08.01

\begin{abstract}
Background: Atrial fibrillation (AF) represents a turning point in hypertrophic cardiomyopathy (HCM). Pulmonary Vein Isolation (PVI) with Radiofrequency Catheter Ablation (RFCA) is accepted to be successful in restoring sinus rhythm (SR) in HCM patients. The efficacy of cryoballoon (CB) therapy in HCM patients has not been studied so far.

Methods: 166 patients with $A F$ underwent $P V I$ with $C B$ technology in our single center between $1 / 2012$ and $12 / 2015$. To evaluate the efficacy of the CB therapy in HCM patients, we compared their clinical outcome with those in "Non-HCM" AF patients in a 3 and 6 months follow-up.

Results: Out of 166 AF patients (65.7\% paroxysmal AF, PAF), 4 patients had HCM and PAF (young males $<50$ years). During the blanking period, 26 patients (15.8\%) suffered from AF recurrence (11.0\% PAF), including all HCM patients. The 6 months follow up of "Non-HCM" AF patients showed acceptable results ( $80 \%$ stable $\mathrm{SR})$, whereas the HCM patients remained AF.

In Conclusion: Even if the $C B$ provides advantages, the single device cannot be recommended in $\mathrm{HCM}$ patients because of early AF recurrences. Anyway, because of the specific hemodynamic changes in HCM patients with AF, ablation should be sought in an early state of its occurrence, then, however, preferably with RFCA.
\end{abstract}

Key words: cryoballoon ablation; hypertrophic cardiomyopathy; atrial fibrillation; follow up

\section{Introduction}

$\mathrm{AF}$ is the most common sustained arrhythmia in $\mathrm{HCM}$ and occurs in $20 \%$ to $25 \%$ of HCM patients [1]. It is often poorly tolerated and is associated with significant clinical deterioration in HCM patients [2, 3]. AF increases in incidence with age, and is linked to left atrial (LA) enlargement reflecting the presence of advanced disease [2]. In the long term, AF is known to be a substantial risk factor for heart failure-related mortality, stroke, and severe functional disability, particularly in HCM patients $<50$ years of age with left ventricular outflow tract obstruction (in about $25 \%$ of all patients with HCM), [3-6].

Although, the more severe clinical course associated with the development of AF in younger HCM patients has not been explained satisfactorily, it is undoubted that the maintenance of sinus rhythm 
(SR) is highly desirable. We know that HCM patients with recent onset of $\mathrm{AF}$, mildly increased atrial size and mild or no symptoms seem to have the greatest potential of obtaining SR and to reduce or postpone the need for pharmacological antiarrhythmic therapy, likely due to lesser degrees of atrial remodeling [7].

In our single center study we investigated in a large group of cryoballoon (CB) ablated AF patients, the feasibility and efficacy of PVI in HCM patients with AF. To our knowledge, that has not been studied so far. We discuss advantages and disadvantages of a single device ablation technique compared with Radiofrequency Ablation (RFCA) and whether this tool is able to influence the outcome in HCM patients with AF. Such data may be of clinical value in the treatment of highly symptomatic young people with this very complex cardiomyopathy.

\section{Methods}

\section{Patients selected, complete study population}

In our single center study we designed a retrospective analysis with $\mathrm{AF}$ patients undergoing CB therapy between $1 / 2012$ and $12 / 2015$ and elucidated HCM patients among "Non-HCM" patients. From the beginning up to April 2012, we used the first-generation $\mathrm{CB}, 28-\mathrm{mm}$ (ArcticFront ${ }^{\mathrm{TM}}$ ), and since November 2012 the second-generation CB, $28 \mathrm{~mm}$ (Arctic FrontAdvanced ${ }^{\mathrm{TM}}$, MedtronicCryocath, Pointe-Claire, Canada). The diagnosis of HCM followed the definition of an unexplained LV hypertrophy associated with non-dilated ventricular chambers in the absence of another cardiac or systemic disease that itself would be capable of producing the magnitude of hypertrophy [8]. In order to evaluate the efficacy of the $\mathrm{CB}$ therapy in $\mathrm{HCM}$ patients, we compared their clinical outcome to those in "Non-HCM" AF patients in a 3 and 6 months follow-up.

\section{Patients selected, HCM patients in detail}

Patient 1 was a 45 years old male and carrier of a dual-chamber ICD. The diagnosis of HCM was made seventeen years ago. He had no catheter-based septum ablation in the past. The long duration of HCM and the systolic anterior movement with moderate mitral regurgitation lead to a dilated LA (Figure 1). Figure 2 shows pressure tracings demonstrating the Brockenbrough-BraunwaldMorrow sign during cardiac catheterization. PAF was first diagnosed ten years before referral. In the past, he had emergent cardioversion on one occasion. He had never been treated with amiodarone; he was on Verapamil and oral anticoagulant therapy. Currently, AF onset resulted in such a hemodynamic impairment that he was subject to intensive care unit. Here an immediate external electrical cardioversion was necessary to stabilize the patient. Even in sinus rhythm the patient suffered from clearly elevated LA pressure as seen in Figure 3.

Patient 2 was a 43 years old male and carrier of a dual-chamber ICD. The diagnosis of HCM was made ten years ago. He had had catheter-based septum ablation in the past. LA had a normal sizing. PAF was first diagnosed two years before referral; he had two episodes of AF and had never required cardioversion. He had never been treated with amiodarone; he was actually on beta-blockers and oral anticoagulant therapy. Actually, he experienced several inappropriate ICD shocks because of $\mathrm{AF}$ with rapid ventricular response (Figure 4).
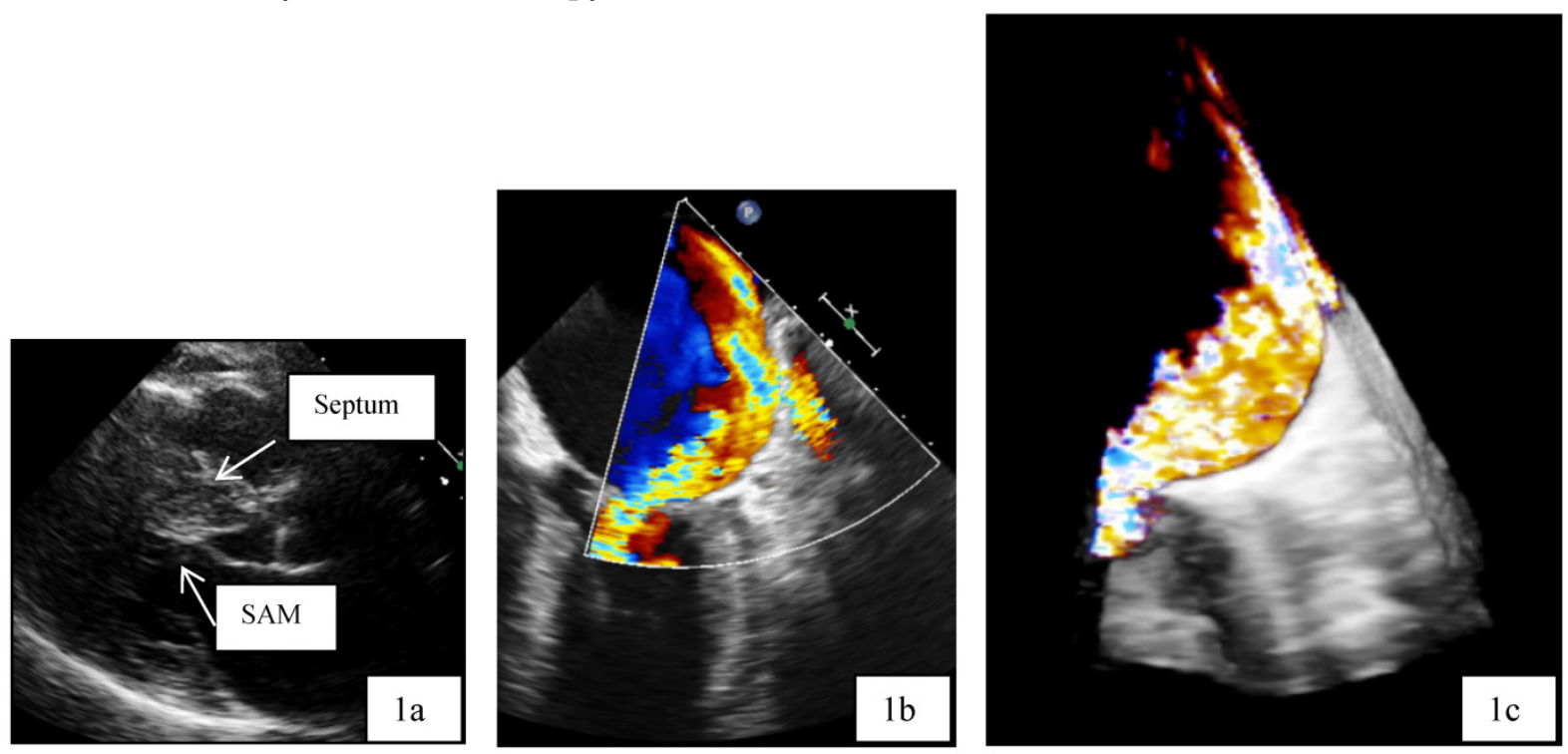

Figure 1. a,b,c: Transthoracic two dimensional echocardiography (2D, la) and transesophageal echocardiography (2D/3D, 1b and $1 \mathrm{c})$ in patient 1 with advanced disease, moderate mitral regurgitation and dilated left atrium. SAM systolic anterior movement. 

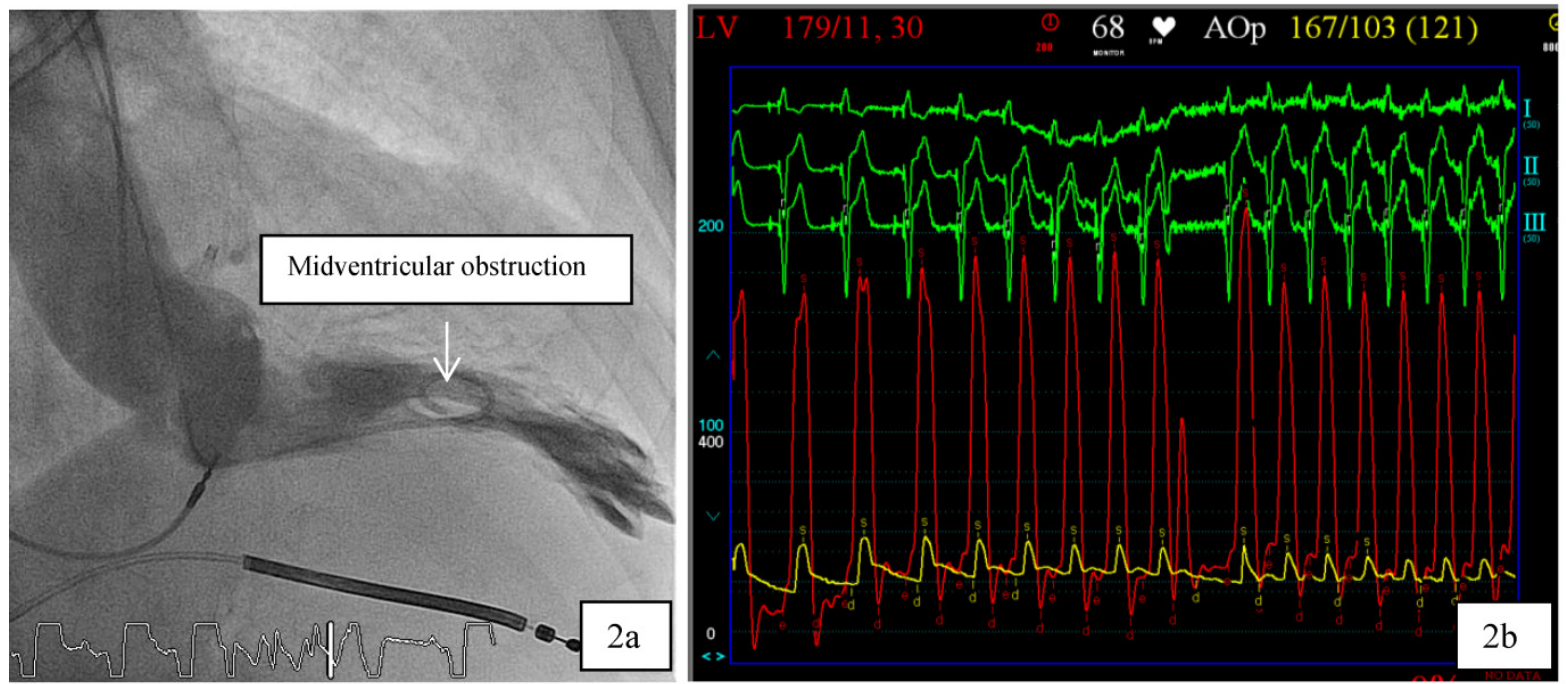

Figure 2. a,b: 2a. In patient 1 , cardiac catheterization with levocardiogram shows midventricular obstruction. $2 \mathrm{~b}$ : From the top to the bottom surface ECG leads I, II, III. Red Curve: Left ventricular (LV) Pressure, yellow curve: Aortic pressure. The tracings demonstrate the Brockenbrough-Braunwald-Morrow sign in HOCM patients as the LV-pressure increases significantly in the post extrasystole period.

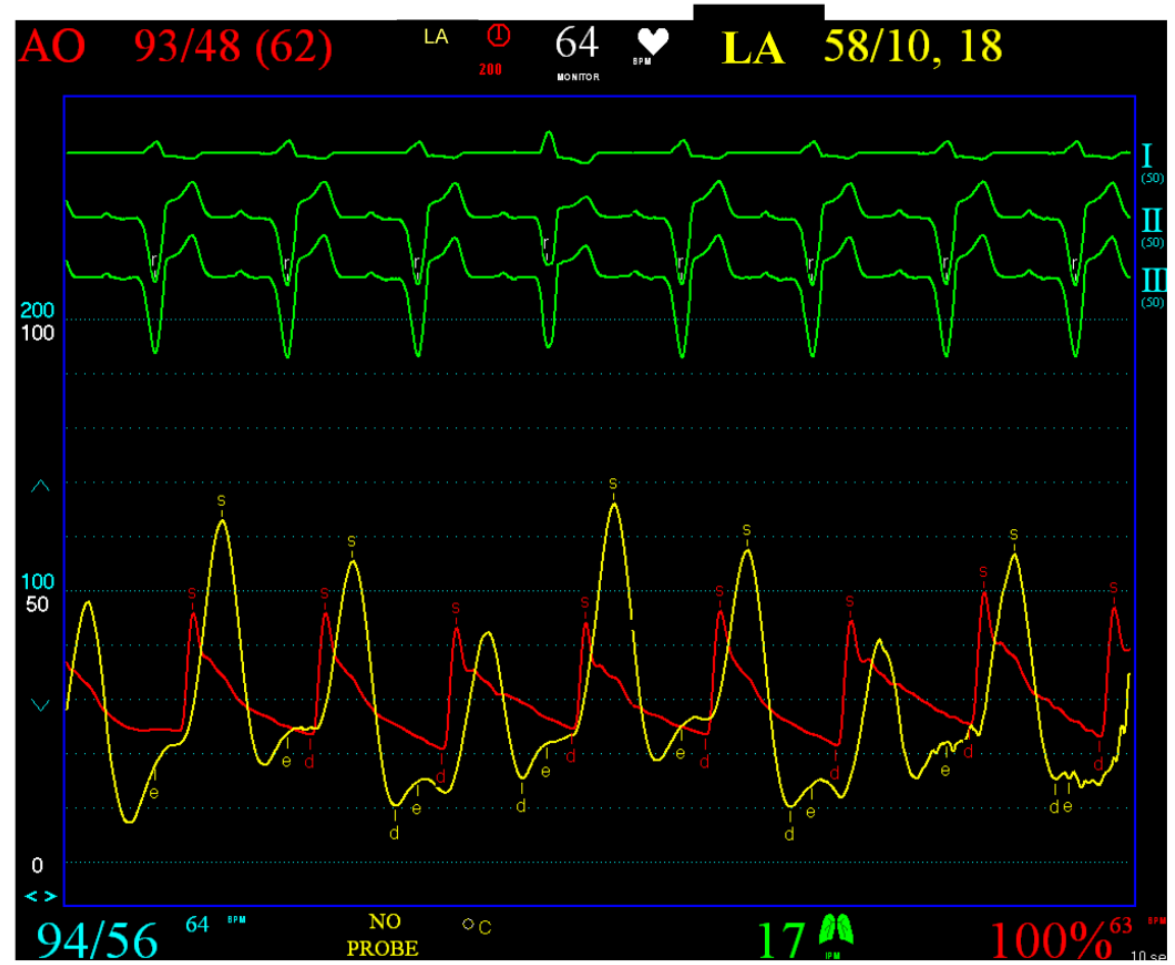

Figure 3. Clearly elevated LA pressure in patient 1, yellow curve, red: aortic curve. From the top to the bottom surface ECG leads I, II, III. Red Curve: AO, Aortic pressure (range 0-200 mmHg). Yellow curve: LA, Left atrial pressure (range 0-100 $\mathrm{mmHg}$ ).

Patient 3 was a 42 years old male and carrier of a dual-chamber ICD. The diagnosis of HCM was made ten years ago. As patient two, he had had catheter-based septum ablation in the past and LA was not dilated. PAF was first diagnosed one year before referral. He had never been treated with amiodarone; he was on beta-blockers and oral anticoagulant therapy. Actually, AF onset resulted in hemodynamic deterioration, with the need for mechanical ventilation.
Patient 4 was a 50 years old male. When admitted in our hospital, he was on propafenone since years due to PAF. AF-related symptoms included several hospital admissions with palpitations and presyncopes. AF converted spontaneously to SR. In the past, only on one occasion external cardioversion was necessary. The diagnosis of HCM was currently made in our hospital, conventionally by imaging the hypertrophic cardiomyopathy with two-dimensional (2D) echocardiography and magnetic resonance 
imaging. LA had a normal sizing. We removed propfenone and gave instead beta-blockers. Furthermore, we added new oral anticoagulant therapy (dabigatran). This patient was not carrier of an ICD.

\section{Procedure management}

Three-dimensional computed tomography reconstruction of the LA was performed to assess the anatomy of the PVs. Transesophageal echocardiography ruled out atrial thrombi. All procedures were performed under conscious sedation and analgesia with propofol and fentanyl. After transseptal puncture (TSP), heparine was maintained to achieve an activated clotting time $>300 \mathrm{~s}$. The technique of PVI with CB therapy has been described extensively [9]. Briefly, after a single TSP, we placed the stiff exchange guidewire in LSPV, and maneuvered the sheath and the AchieveTM towards the LSPV to facilitate the advancement of the balloon. The single application time was 240-300s per freeze.
During CB ablation of the right-sided PV, unaffected phrenic movement was monitored by both continuous phrenic nerve (PN) stimulation and continuous monitoring of spontaneous breathing. The isolation was verified as complete elimination of all PV signals at the antral or ostial level. Additionally, exit and entrance-block of all veins were confirmed on pacing maneuvers.

\section{Follow-Up}

The follow-up was performed at 3 and 6 months after the procedure, with physical examination, 12-lead ECG, and 7-day Holter monitoring. Recurrence was considered to be any episode of $\mathrm{AF} /$ atrial tachycardia lasting for $\geq 30$ seconds after a blanking period of 3 months from the procedure. Repeat ablation was not allowed during the blanking period. Antiarrhythmic drugs were systematically used for the blanking period and discontinued after the end of the blanking period if patients were in sinus rhythm.

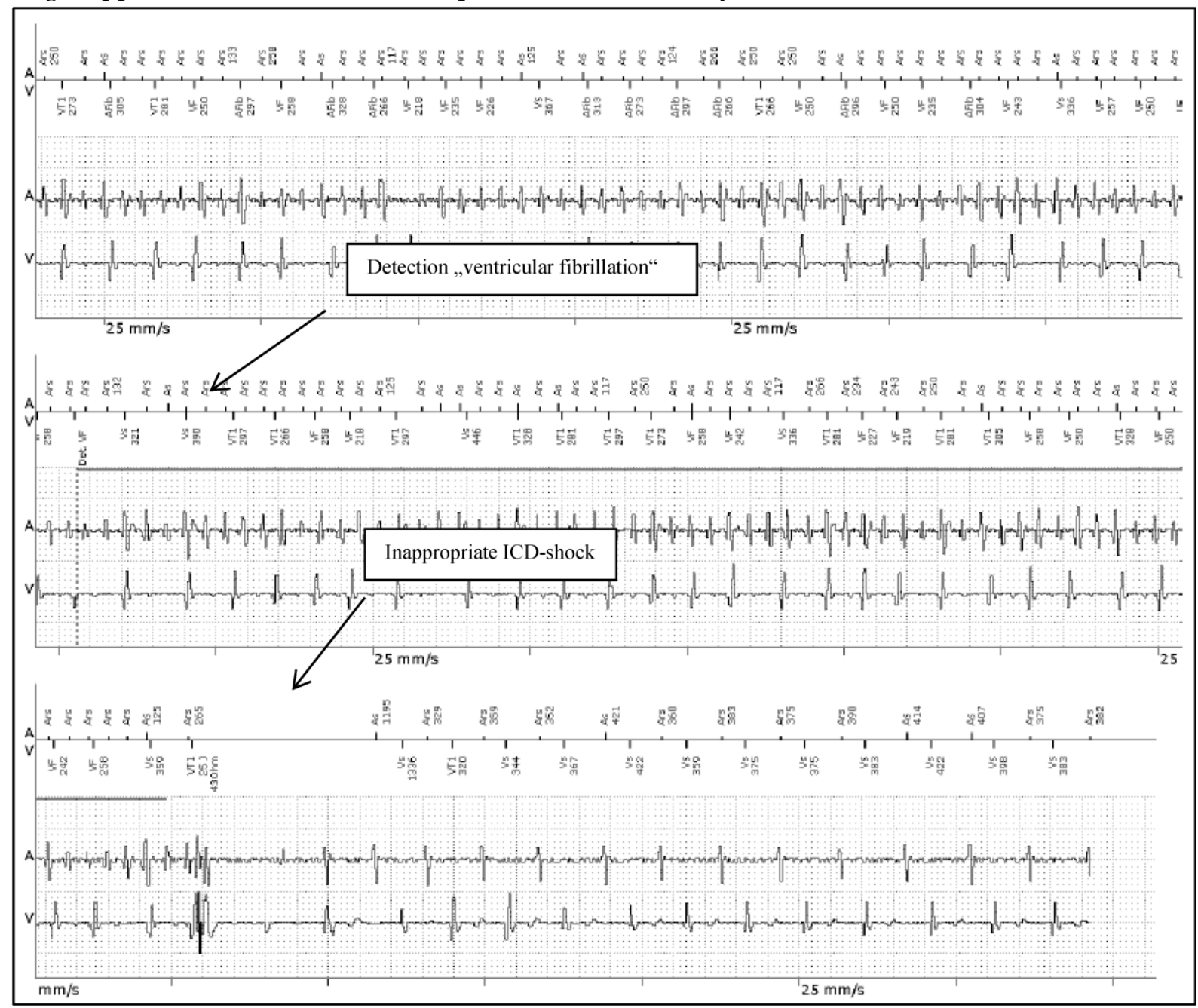

Figure 4. Inappropriate ICD shock therapy in patient 2 after detection of "VF" (ventricular fibrillation) due to AF with rapid ventricular response. From the top to the bottom: Upper line, A: Atrial channel with atrial sensing and atrial cycle length. $\mathrm{V}$ : Ventricular channel with alteration marking from VS=Ventricular sense to $\mathrm{VT}=\mathrm{Ventricular}$ Tachycardia and VF=Ventricular Fibrillation. Lower line $\mathrm{A} / \mathrm{V}$ : Atrial and Ventricular intra-cardiac electrogram. 


\section{Statistical analysis}

All data was presented as mean \pm standard deviation (SD). SPSS 22.0 software package was used for statistical analysis. Student's t-test and Chi-square test were used to determine the statistical significance of differences of numerical and categorical data. A p value of $<0.05$ was statistically significant. 6-months arrhythmia-free survival was reported as crude event rates and assessed through a time-to-event analysis by the Kaplan-Meier method.

\section{Results}

\section{Characteristics of all AF patients}

This retrospective analysis enrolled 166 patients with symptomatic PAF and persistent AF (persAF) undergoing PVI. Table 1 shows the baseline characteristics of the patients. They were $63.0 \pm 11.4$ years old, 109 patients had PAF $(65.7 \%), 57$ patients persAF $(34.3 \%)$, with duration of in mean 33 months (range 1 month to 240 months). In the three-dimensional computed tomography reconstruction of the LA, we found a normal PV anatomy in 139 AF patients (83.7\%). 12 AF patients (7.2\%) had a left common trunk, and 15 AF patients $(9.0 \%)$ had an accessory vein on the right side.

Table 1: Clinical Characteristics of the Patients Included in the Study. Values are expressed as mean $\pm S D$ or $n(\%) . A F=$ Atrial fibrillation. ${ }^{*}$ Chi-Quadrat-test $p=0.002$.

\begin{tabular}{ll}
\hline Variable & $\mathrm{N}=166$ \\
\hline Age (y) & $63.0 \pm 11.4$ \\
Sex (males) & $92(55.4 \%)$ \\
AF type & \\
paroxysmal & $109(65.7 \%)$ \\
persistent & $57(34.3 \%)$ \\
AF duration (month) & $32.6 \pm 11.4$ \\
LA diameter (mm) & $4.8 \pm 2.5$ \\
No coronary vessel disease & $124(74.7 \%)$ \\
LV ejection fraction & \\
normal & $154(92.8 \%)$ \\
Failed antiarrythmic drugs & \\
Class Ic agents & $48(28.9 \%)$ \\
Amiodarone & $22(13.3 \%)$ \\
Sotalol & $3(1.8 \%)$ \\
Dronedarone & $12(7.2 \%)$ \\
Ablation tool & \\
ArcticFront ${ }^{\mathrm{TM}}\left(1^{\text {st }}\right.$ generation), $\mathrm{n}$ & $45(27.1 \%)$ \\
Arctic FrontAdvanced & \\
Complete Pulmonary $\left(2^{\mathrm{st}}\right.$ gein Isolation, $\mathrm{n}$ & $121(72.9 \%)$ \\
ArcticFront & \\
Arctic FrontAdvanced ${ }^{\text {st }}$ generation), $\mathrm{n}$ & $156(94 \%)$ \\
Total procedure time (min) & $38(84.4 \%)$ \\
\hline
\end{tabular}

\section{Characteristics of HCM patients with AF}

Out of 166 AF patients, we found 4 patients with HCM (Table 2 shows their details: all males, age between 42 and 50 years, all ablated after November
2012 with the second-generation CB). Their functional status during SR was New York Heart Association (NYHA) class II. Three HCM patients were carrier of a dual-chamber ICD. AF-related symptoms in all HCM patients included palpitations, presyncopes, hypotension, dyspnea, and inappropriate shocks. In the three-dimensional computed tomography reconstruction of the LA, we found a normal PV anatomy.

Table 2: Clinical Characteristics of the four HCM Patients with AF Included in the Study HCM Hypertrophic cardiomyopathy; TASH transfemoral alcohol septal ablation; ICD Interner Cardioverter; CVD Cardiovascular disease; LV Left Ventricle; AF Atrial Fibrillation; LA Left Atrium; OAK Oral Anticoagulant Therapy. * diagnosed with HCM when admitted in our hospital

\begin{tabular}{|c|c|c|c|c|}
\hline & Patient 1 & Patient 2 & Patient 3 & Patient $4^{*}$ \\
\hline Age, y & 45 & 43 & 42 & 50 \\
\hline Sex & male & male & male & male \\
\hline $\begin{array}{l}\text { HCM, first } \\
\text { diagnosed }\end{array}$ & 17 years & 12 & 10 & actually \\
\hline TASH & no & yes & yes & no \\
\hline ICD & yes & yes & yes & no \\
\hline $\begin{array}{l}\text { Inadequate } \\
\text { Schocks }\end{array}$ & no & yes & no & no \\
\hline CVD & no & no & no & no \\
\hline $\begin{array}{l}\text { LV ejection } \\
\text { fraction }\end{array}$ & normal & normal & normal & normal \\
\hline $\mathrm{AF}$ & persAF & PAF & PAF & PAF \\
\hline $\begin{array}{l}\text { AF duration, } \\
\text { months }\end{array}$ & 120 & 24 & 12 & 48 \\
\hline LA diameter, $\mathrm{cm}$ & 5.6 & 3.4 & 3.9 & 4.1 \\
\hline $\begin{array}{l}\text { Prior } \\
\text { Cardioversion }\end{array}$ & 1 (emergent) & 0 & 0 & 1 (emergent) \\
\hline In Sinusrhythm & NYHA II & NYHA I & NYHA II & NYHA II \\
\hline Rate control in SR & Verapamil & Betablocker & Betablocker & PAF \\
\hline $\begin{array}{l}\text { Antiarrythmic } \\
\text { drugs }\end{array}$ & 0 & 0 & 0 & Propafenon \\
\hline OAK & Marcumar & Marcumar & Marcumar & Dabigatran \\
\hline $\begin{array}{l}\text { Acute } \\
\text { decompensated } \\
\text { heart failure }\end{array}$ & $\begin{array}{l}\text { AF, emergent } \\
\text { cardioversion }\end{array}$ & $\begin{array}{l}\mathrm{AF} \\
\text { inadequate } \\
\text { ICD shocks }\end{array}$ & $\begin{array}{l}\mathrm{AF}, \\
\text { mechanical } \\
\text { ventilation }\end{array}$ & $\begin{array}{l}\text { AF, repeated } \\
\text { hospital } \\
\text { admission }\end{array}$ \\
\hline PV anatomy & 4 veins & 4 veins & 4 veins & 4 veins \\
\hline $\begin{array}{l}\text { Pulmonary Vein } \\
\text { Potentials }\end{array}$ & all 4 veins & all 4 veins & all 4 veins & all 4 veins \\
\hline Cryoballoon & $\begin{array}{l}2^{\text {nd }} \\
\text { generation }\end{array}$ & $\begin{array}{l}2^{\text {nd }} \\
\text { generation }\end{array}$ & $\begin{array}{l}2^{\text {nd }} \\
\text { generation }\end{array}$ & $\begin{array}{l}2^{\text {nd }} \\
\text { generation }\end{array}$ \\
\hline PVI & complete & complete & complete & complete \\
\hline $\begin{array}{l}\text { Total procedure } \\
\text { time, min }\end{array}$ & 140 & 120 & 120 & 100 \\
\hline
\end{tabular}

\section{PVI results of all AF patients}

All patients underwent the procedure with the $28 \mathrm{~mm} \mathrm{CB}$, whereas in 45 patients $(27.9 \%)$ the first-generation $\mathrm{CB}$ was used, and in 121 patients (72.9\%) the second-generation CB. After a mean of 2.1 applications in all veins, complete PVI was achieved in $156 \mathrm{AF}$ patients (94\%). Due to the patients anatomy, suboptimal balloon positioning and occlusion lead to incomplete isolation of in total $10 \mathrm{PV}$ (7 with the first-generation $\mathrm{CB}$, and 3 with the 
second-generation $\mathrm{CB}$ ). In 2 patients, the LSPV was incompletely isolated, in 1 patient the LIPV, in 2 patients the RSPV, and in 5 patients the RIPV. Comparing the procedural success of the first-generation $\mathrm{CB}$ to the second-generation $\mathrm{CB}$, the complete PVI with the second-generation CB succeeded significantly more often $(84.4 \%$ respective $97.5 \%$, Chi-Quadrat-test $\mathrm{p}=0,002$ ). Total procedural time was $119.3 \pm 30$ minutes. Mean minimal temperatures were $-50.6 \pm 5.9^{\circ} \mathrm{C}$ in the LSPV, $-45.7 \pm$ $9.1^{\circ} \mathrm{C}$ in the LIPV, $-49.5 \pm 8.3^{\circ} \mathrm{C}$ in the RSPV and -44.0 $\pm 10.5^{\circ} \mathrm{C}$ in the RIPV.

\section{PVI results in HCM patients}

All 4 patients underwent the procedure with the second-generation CB, $28 \mathrm{~mm}$. With the Mapping catheter Achieve ${ }^{\mathrm{TM}}$, we found PV potentials in all veins. After a mean of 2.2 applications, all veins were isolated (e.g. Figure 5). Total procedure time was 140, twice 120 and 100 minutes, respectively. Mean minimal temperatures reached in the LSPV were $-49.1 \pm 5.4^{\circ} \mathrm{C}$, in the LIPV $-50.6 \pm 11.58^{\circ} \mathrm{C}$, in the RSPV $-51.3 \pm 4.1^{\circ} \mathrm{C}$, and $-43.0 \pm 6.6^{\circ} \mathrm{C}$ in the RIPV.

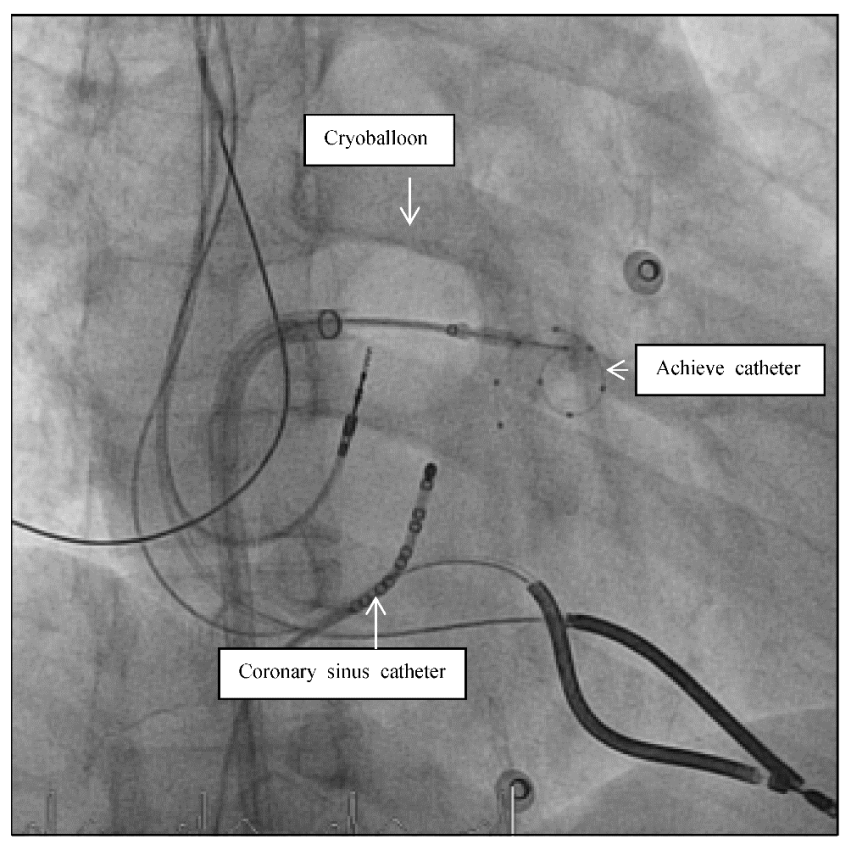

Figure 5. Fluoroscopic view during AF ablation in Right Anterior Oblique view (RAO 30). Pulmonary vein isolation in the left inferior pulmonary vein with the second generation of the cryoballoon technology. The mapping catheter (Achieve catheter) is deep in the pulmonary vein, as the ablation catheter (cryoballon) is attached to the PV-ostium. The coronary sinus catheter is introduced in the coronary sinus for orientation and stimulation purposes.

\section{Short- and longterm follow up of all AF patients}

During intervention, phrenic nerve paralysis occurred in 10. Pericardial effusion occurred in 2 patients $(1.2 \%)$, and could be managed conservatively; one neurological event occurred in 1 patient $(0.6 \%)$, eight hours after the procedure. As far as the follow up, table 3 shows the details of the 3 and 6 months follow up. In total, 10 patients $(6.0 \%)$ were lost after 6 months; 2 patients (1.2\%) died due to a non- cardiac disease. During the blanking period of 3 months, 26 patients (15.8\%) suffered episodes of AF (12 patients with PAF, $11.0 \%$, and 14 patients with persAF, 25.0\%). After 6 months 129 patients (77.7\%) were in stable SR (89 patients with PAF, $82.4 \%$, and 40 patients with persAF, $71.4 \%$ ). In 6 patients with recurrence of $\mathrm{AF}(3.6 \%)$, a re-do procedure with RFCA was performed $>4$ months after the index procedure.

Table 3: Follow up of all AF patients three and six month after the index procedure. ${ }^{*}$ Chi-Quadrat-test $\mathrm{p}=0.005$.

\begin{tabular}{|c|c|c|}
\hline Variable $\mathrm{n}=166$ & 3 months & 6 months \\
\hline Lost to follow-up, $\mathrm{n}$ & $7(4.2 \%)$ & $10(6.0 \%)$ \\
\hline Death, non cardiac & $1(0.6 \%)$ & $1(0.6 \%)$ \\
\hline Stable Sinusrhythm & $132(79.5 \%)$ & $129(77.7 \%)$ \\
\hline PAF & $93(85.3 \%)$ & $89(82.4 \%)$ \\
\hline Pers AF & $39(69.6 .0 \%)^{*}$ & $40(71.4 \%)$ \\
\hline AF recurrences & $26(15.8 \%)$ & $25(15.2 \%)$ \\
\hline PAF & $12(11.0 \%)$ & $12(11.1 \%)$ \\
\hline Pers AF & $14(25.0 \%)^{*}$ & $13(23.2 \%)$ \\
\hline \multicolumn{3}{|l|}{ Ablation tool } \\
\hline ArcticFront ${ }^{\mathrm{TM}}$ (1 $1^{\text {st }}$ generation) & $45(27.1 \%)$ & $45(27.1 \%)$ \\
\hline Stable Sinusrhythm & $29(65.9 \%)$ & $31(70.5 \%)$ \\
\hline Arctic FrontAdvanced ${ }^{\mathrm{TM}}$ ( $2^{\text {st }}$ generation $)$ & $121(72.9 \%)$ & $121(72.9 \%)$ \\
\hline Stable Sinusrhythm & $103(85.1 \%)^{*}$ & $98(81.7 \%)$ \\
\hline
\end{tabular}

\section{Short- and longterm follow up of HCM patients}

No procedure complications occurred. All HCM patients had an uneventful clinical course. Oral anticoagulation was continued and all patients were discharged the next days. In the follow up, all HCM patients suffered from early AF recurrences within the first three months (blanking period). Taking the small subgroup of in total 12 patients with PAF and recurrence of $\mathrm{AF}$ during the blanking period, we found our $4 \mathrm{HCM}$ patients in this subgroup. The Kaplan-Meier curve for AF free survival for all AF patients at 6 months illustrates the worst short-term $\mathrm{AF}$ free survival with high recurrence rate of $\mathrm{AF}$ in the patients with HCM (Figure 6). In the further follow up, patient 1 underwent a re-do procedure with RFCA after 4 months. We found atypical left atrial flutter that was ablated successfully drawing a roof line and a mitral isthmus line. The following month AF occurred again as we saw in the ICD interrogation; it was better tolerated, so that the patient refused further interventions. Patient 2 and 4 received temporarily amiodarone in the blanking period and refused further interventions. They have been in 
permanent $\mathrm{AF}$ for 12 months. Clinically, they tolerated AF better, no further hospital admissions were necessary. Patient 3 underwent a surgical AF ablation after 1 year after the index procedure.

\section{Discussion}

Since the early PVI advances in the treatment of $\mathrm{AF}$, the $\mathrm{CB}$ therapy has been experiencing increasing importance in terms of their faster feasibility in comparison to RFCA. We see the need to provide data of PVI results in patients with complex hemodynamics as those with HCM. In $166 \mathrm{AF}$ patients, we showed that $\mathrm{CB}$ therapy failed to maintain SR in this patient group.

The charm of the electrophysiological guided CB ablation in comparison to the irrigated-tip RFCA is in the 1) often shorter procedure time, the 2) only once to do transseptal puncture and the 3) lack of added volume administration in the often dilated and volume overloaded LA. Even more disappointing is the fact that - in comparison to the Non-HCM patients - already in the blanking period the CB ablation leads to partly unchanged frequent AF recurrences in all HCM patients.

\section{Pathophysiological aspects in patients with HCM and AF}

Over time, already in rest, due to the myocardial hypertrophy with impaired left ventricular (LV)

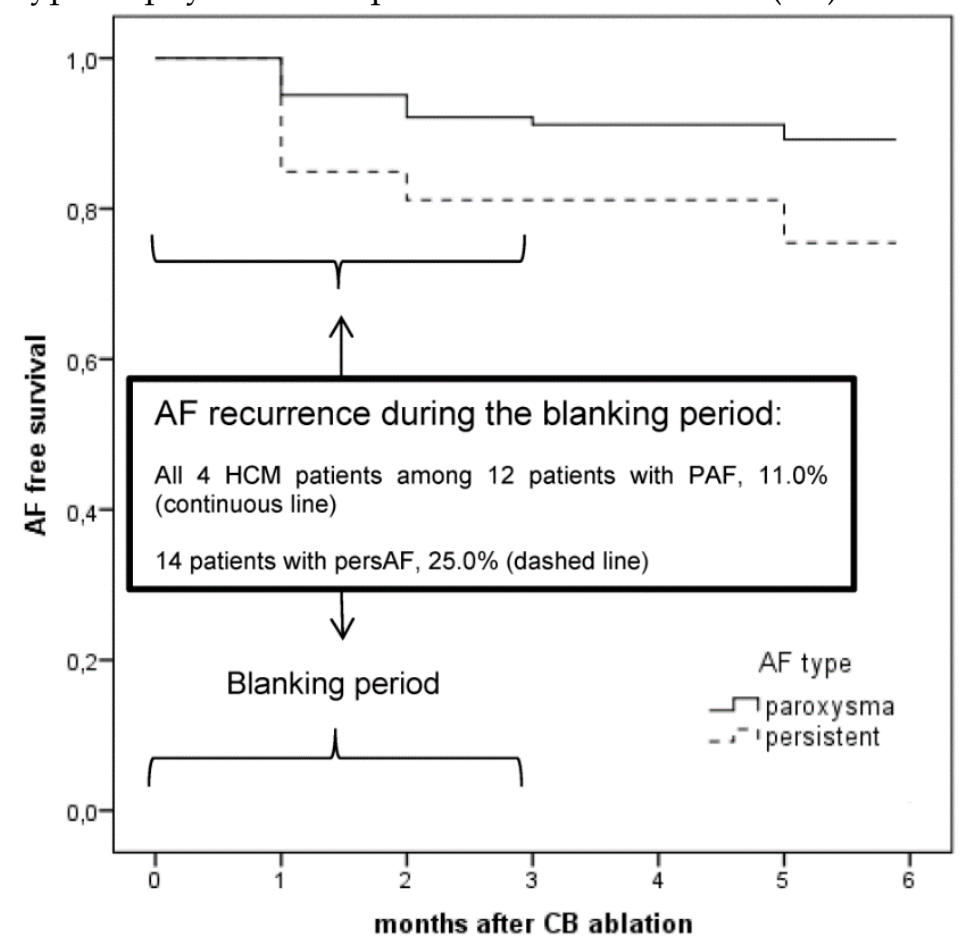

Figure 6. Kaplan-Meier curve of all patients with atrial fibrillation (AF) including patients with and without hypertrophic cardiomyopathy $(\mathrm{HCM})$ for $\mathrm{AF}$ free survival at 6 months. AF in $\mathrm{HCM}$ conferred worst short-term AF free survival than for those PAF patients without $\mathrm{HCM}$. relaxation during early diastolic filling, the LV end diastolic volumes decrease and the LV end diastolic pressures increase. To improve the ventricular filling during diastole, atrial contraction increases, and in patients with HCM, most of the LV inflow volumes are contributed by atrial contraction - in other words: SR becomes mandatory to maintain the complex hemodynamic balance in HCM with and without obstruction. When HCM is complicated by AF with tachycardia, the sudden loss of atrial contraction decreases primarily the cardiac output, and leads secondarily to the development of sometimes severe acute heart failure.

\section{Medical therapy in patients with HCM and AF}

Previous studies have shown that converting and maintaining SR pharmacologically is sometimes effective, e.g. Disopyramide (with ventricular rate-controlling agents) and amiodarone [10, 11], but due to its side effects and limited long-term efficacy, amiodarone cannot be a real option to maintain SR [2]. To reduce or postpone the need for pharmacological antiarrhythmic therapy, radiofrequency catheter ablation (RFCA) has emerged as a feasible and safe treatment strategy with satisfactory short- and midterm results for symptomatic drug-resistant $\mathrm{AF}$ even in advanced disease and severe dilatation of the LA [7,12-16]. Taking the last updated guidelines on the management of AF in the general population [17], where the use of catheter ablation in selected patients as first-line therapy for paroxysmal AF (PAF) is recommended, one could hypothesize that HCM patients could also benefit from early pulmonary vein isolation (PVI), although in so far as it is still unclear whether pulmonary vein (PV) triggering alone is the underlying pathophysiological mechanism in HCM [18].

\section{RFCA in HCM patients}

There is consensus that especially young HCM patients with small atrial size and mild symptoms proved to be the best RF candidates, likely due to lesser degrees of atrial remodelling. Some groups could show the feasibility, safety and long term efficacy of RF ablation in HCM cohorts including patients in later stages of the disease with a relatively long history of AF, who had failed serial antiarrhythmic drug testing; ablation had lead them to improved functional status and reduced need for long-term pharmacologic treatment [7,12-16], even if redo procedures were often necessary [13]. The reason of the success of RFCA PVI in HCM patients remains 
uncertain as the pathophysiological aspects of AF in $\mathrm{HCM}$ are not well understood. The success is possibly explained with the wide antral isolation that might hypothetically affect the periosteal nervous system and reduce its influence on these structures. This reduced influence of the nervous system, also described to be present in the second generation of $\mathrm{CB}$ catheters, maybe leads to a reduction in the tachycardia rate and thus to an improvement of the clinical tolerance (as in patient 1, 2 and 4 who refused further intervention in permanent $\mathrm{AF}$ ) and a decrease in the risk of inappropriate ICD shocks (as in patient 3 , who suffered several AF episodes without further ICD shocks).

\section{Cryoballoon Therapy in AF}

While focal RF catheters have been the standard-of-care for AF ablation [17], balloon-based technologies were developed in an attempt to deliver ablative energy in a more continuous pattern without conduction gaps during cardiac tissue isolation [19, 20]. The second generation cryoballoon (CB; Arctic Front AdvanceTM) was released in 2012, and it was designed to achieve more uniform cooling across the entire distal hemisphere of the balloon using eight injection tubes versus the original four-port design in the first generation of $\mathrm{CB}[21,22]$. Acutely, the time to achieve PVI has shortened and acute PV reconnection is rare, and chronically, freedom from AF seems to be higher in non-randomized studies [21-27]. Moreover, the rates of $\mathrm{PV}$ reconnection in patients with recurrent $\mathrm{AF}$ are remarkably low compared with historic controls [28].

\section{CB ablation in our HCM patients}

Our four HCM patients reflect very well the diversity of clinical severe signs and therefore the complexity of this heart disease. The sudden onset of AF with the loss of atrial systole and the uncontrolled fast ventricular beats lead in all our patients to severe hemodynamic deterioration with hypotension, heart failure, necessity of non-invasive ventilation and furthermore, inappropriate shock therapies in carriers of an ICD. Common to all our patients is their young age and for this already very long history of the underlying disease (all between 42 and 50 years, HCM known since about 10 years). AF in these patients did not occur for the first time but taking the history in detail, AF may be described as PAF. No antiarrhythmic drugs were used in all patients. Common to them is also - in accordance with the chronic course of AF - that the episodes of $\mathrm{AF}$ mounted up and were associated with frequent hospital admissions. Our patient 4 in particular shows how difficult it can be to make the diagnosis of HCM.
This example raises the question, of how many undetected young HCM patients with PAF have falsely been treated for years with antiarrhythmic drugs of class IIc.

\section{Reasons for the worst short-term AF free survival in CB ablated HCM patients}

In contrast to previous findings in studies using RFCA to isolate the PVs (see below) in HCM patients, our data demonstrated a worse short-term outcome in the HCM patients with AF but using $\mathrm{CB}$. The reason for the very high and early recurrence rate in our HCM patients is not clear. Surely, one would have been able to increase the probability of long term success if we had tried to induce AF at the end of the procedure by burst pacing or adenosine to exclude an early PV reconnection, but this is probably of minor importance. Unfortunately, we cannot provide substantiation if the PVs are reconnected or not, because only one patient has been followed up in a redo procedure. Maybe the recurrence rate of $\mathrm{AF}$ was so high, because CB eliminates focal triggers in PVs but cannot be expected to reach non-PV triggers that might exist in HCM patients. Furthermore, we did not look after other triggers than PV potentials during the procedure. The only case report in the literature describing successful PVI with the CB technology in a 42-year-old man - with a history of HCM - and highly symptomatic paroxysmal drug-resistant AF [29], the author did an additional ablation of an endocardial focus with fractionated potentials at the base of the left appendage that finally terminated the episode of AF. No recurrence of AF was observed during a 10-month follow-up period.

\section{Conclusion}

Although we found "ideal" conditions in our CB treated HCM patients concerning age and anatomical status, and although CB was potentially feasible and successful regarding the isolation of the PVs, PVI with CB technology failed to maintain SR even in the early observation period after ablation and can therefore not be recommended. However, in general there should be no doubt that an early nonpharmacologic treatment in the absence of antiarrhythmic therapy options seems reasonable in this cohort to attenuate the symptoms of the affected patients and prevent frequent hospitalizations. Yes, it seems reasonable, although we know that progressive atrial remodeling, specific to the HCM disease process [30], may influence the outcome of PVI, even if the procedure is initially successful. Irrespective of the underlying mechanism in HCM patients, RF ablation of AF seems to be the most efficient strategy to treat this arrhythmia in an early state of its occurrence. 


\section{Limitations of the present study}

The small number of patients included is certainly a limitation but it does not seem to be very likely that a more extensive study is needed to confirm our preliminary observations. For that, we could well document the acute success with complete PVI after the CB ablation and the poor follow up with early AF recurrences in the blanking period.

\section{Abbreviations}

\author{
AF: Atrial Fibrillation \\ CB: Cryoballoon \\ ICD: Implantable Cardioverter Defibrillator \\ LA: Left Atrium \\ LV: Left Ventricle \\ PAF: Paroxysmal Atrial Fibrillation \\ PersAF: Persistent Atrial Fibrillation \\ PV: Pulmonary Vein \\ PVI: Pulmonary Vein Isolation \\ RF: Radiofrequency \\ RFCA: Radiofrequency Catheter Ablation \\ SR: Sinus Rhythm \\ TSP: Transseptal Puncture
}

\section{Conflict of interests}

On behalf of all authors, the corresponding author states that there is no conflict of interest.

\section{References}

1. Maron BJ Hypertrophic cardiomyopathy: a systematic review. JAMA. 2002 Mar 13;287(10):1308-20.

2. Robinson K, Frenneaux MP, Stockins B, Karatasakis G, Poloniecki JD, McKenna WJ. Atrial fibrillation in hypertrophic cardiomyopathy: a longitudinal study. J Am Coll Cardiol 1990;15:1279-85.

3. Olivotto I, Cecchi F, Casey SA, Dolara A, Traverse JH, Maron BJ. Impact of atrial fibrillation on the clinical course of hypertrophic cardiomyopathy. Circulation. 2001 Nov 20;104(21):2517-24.

4. Maron MS, Olivotto I, Betocchi S, Casey SA, Lesser JR, Losi MA, Cecchi F, Maron BJ. Effect of left ventricular outflow tract obstruction on clinical outcome in hypertrophic cardiomyopathy. N Engl J Med. 2003 Jan 23;348(4):295-303.

5. Maron BJ, Casey SA, Poliac LC, Gohman TE, Almquist AK, Aeppli DM. Clinical course of hypertrophic cardiomyopathy in a regional United States cohort. JAMA. 1999 Feb 17;281(7):650-5

6. Siontis KC, Geske JB, Ong K, Nishimura RA, Ommen SR, Gersh BJ. Atrial fibrillation in hypertrophic cardiomyopathy: prevalence, clinical correlations, and mortality in a large high-risk population. J Am Heart Assoc. 2014 Jun $25 ; 3(3)$.

7. Di Donna P, Olivotto I, Delcrè SD, Caponi D, Scaglione M, Nault I, Montefusco A, Girolami F, Cecchi F, Haissaguerre M, Gaita F. Efficacy of catheter ablation for atrial fibrillation in hypertrophic cardiomyopathy: impact of age, atrial remodelling, and disease progression. Europace. 2010 Mar;12(3):347-55.

8. Maron BJ, McKenna WJ, Danielson GK, et al. American College of Cardiology/European Society of Cardiology clinical expert consensus document on hypertrophic cardiomyopathy. J Am Coll Cardiol. 2003; 42:1687-713.

9. Chun KR, Schmidt B, Metzner A, Tilz R, Zerm T, Köster I et al. The 'single big cryoballoon' technique for acute pulmonary vein isolation in patients with paroxysmal atrial fibrillation: a prospective observational single centre study. Eur Heart J. 2009 Mar;30(6): 636.

10. Fuster V, Ryden LE, Cannom DS, et al 2011 ACCF/AHA/HRS Focused Updates Incorporated Into the ACC/AHA/ESC 2006 Guidelines for the Management of Patients With Atrial Fibrillation. Circulation. 2011;123:e269-367.

11. Gersh BJ, Maron BJ, Bonow RO, Dearani JA, Fifer MA, Link MS, et al. 2011 $\mathrm{ACCF} / \mathrm{AHA}$ guideline for the diagnosis and treatment of hypertrophic cardiomyopathy: A report of the American College of Cardiology
Foundation/American Heart Association Task Force on Practice Guidelines. Circulation 2011; 124: $783-831$

12. Bunch TJ, Munger TM, Friedman PA, et al. Substrate and procedural predictors of outcomes after catheter ablation for atrial fibrillation in patients with hypertrophic cardiomyopathy. J Cardiovasc Electrophysiol. 2008;19:1009-14.

13. Gaita F, Di Donna P, Olivotto I, et al. Usefulness and safety of transcatheter ablation of atrial fibrillation in patients with hypertrophic cardiomyopathy. Am J Cardiol. 2007;99:1575-81.

14. Kilicaslan F, Verma A, Saad E, et al. Efficacy of catheter ablation of atrial fibrillation in patients with hypertrophic obstructive cardiomyopathy. Heart Rhythm. 2006;3:275-80.

15. Callans DJ. Ablation of atrial fibrillation in the setting of hypertrophic cardiomyopathy. J Cardiovasc Electrophysiol. 2008;19:1015-6.

16. Liu X, Ouyang F, Kuck KH. Complete pulmonary vein isolation guided by three-dimensional electroanatomical mapping for the treatment of paroxysmal atrial fibrillation in patients with hypertrophic obstructive cardiomyopathy. Europace. 2005 Sep;7(5):421-7.

17. 1.Calkins H, Kuck KH, Cappato R, et al, Heart Rhythm Society Task Force on Catheter and Surgical Ablation of Atrial Fibrillation. 2012 HRS/EHRA/ECAS expert consensus statement on catheter and surgical ablation of atrial fibrillation: recommendations for patient selection, procedural techniques, patient management and follow-up, definitions, endpoints, and research trial design: a report of the Heart Rhythm Society (HRS) Task Force on Catheter and Surgical Ablation of Atrial Fibrillation. Heart Rhythm. 2012 Apr;9(4):632-696.

18. Santangeli P, Di Biase L, Themistoclakis S, Raviele A, Schweikert RA, Lakkireddy D, Mohanty P, Bai R, Mohanty S, Pump A, Beheiry S, Hongo R, Sanchez JE, Gallinghouse GJ, Horton R, Dello Russo A, Casella M, Fassini G, Elayi CS, Burkhardt JD, Tondo C, Natale A. Catheter ablation of atrial fibrillation in hypertrophic cardiomyopathy: long-term outcomes and mechanisms of arrhythmia recurrence. Circ Arrhythm Electrophysiol. 2013 Dec;6(6):1089-94.

19. Avitall B, Urboniene D, Rozmus G, Lafontaine D, Helms R, Urbonas A. New cryotechnology for electrical isolation of the pulmonary veins. J Cardiovasc Electrophysiol. 2003 Mar;14(3):281-6.

20. Van Belle Y, Janse P, Rivero-Ayerza MJ, Thornton AS, Jessurun ER, Theuns D, Jordaens L. Pulmonary vein isolation using an occluding cryoballoon for circumferential ablation: feasibility, complications, and short-term outcome. Eur Heart J. 2007 Sep;28(18):2231-7.

21. Knecht S, Kühne M, Osswald S, Sticherling C. Quantitative assessment of a second generation cryoballoon ablation catheter with new cooling technology-a perspective on potential implications on outcome. J Interv Card Electrophysiol. 2014 Jun;40(1):17-21.

22. Coulombe $\mathrm{N}$, Paulin $\mathrm{J}, \mathrm{Su} \mathrm{W}$. Improved in vivo performance of second-generation cryoballoon for pulmonary vein isolation. J Cardiovasc Electrophysiol. 2013 Aug;24(8):919-25.

23. Aytemir K, Gurses KM, Yalcin MU, Kocyigit D, Dural M, Evranos B et al. Safety and efficacy outcomes in patients undergoing pulmonary vein isolation with second-generation cryoballoon. Europace 2014; doi:10.1093/europace/euu273.

24. Fürnkranz A, Bordignon S, Dugo D, Perotta L, Gunawardene M, Schulte-Hahn $\mathrm{B}$ et al. Improved 1-year clinical success rate of pulmonary vein isolation with the second generation cryoballoon in patients with paroxysmal atrial fibrillation. J Cardiovasc Electrophysiol 2014;25:840-4.

25. Metzner A, Reissmann B, Rausch P, Mathew S,Wohlmuth P, Tilz R et al. One-year clinical outcome after pulmonary vein isolation using the second-generation $28 \mathrm{~mm}$ cryoballoon. Circ Arrhythm Electrophysiol 2014;7:288-92.

26. Chierchia G-B, Di Giovanni G, Ciconte G, de Asmundis C, Conte G, Sieira-Moret $J$ et al. Second-generation cryoballoon ablation for paroxysmal atrial fibrillation: 1-year follow-up. Europace 2014:16:639-44.

27. Jourda F, Providencia R, Marijon E, Bouzeman A, Hireche H, Khoueiry Z et al. Contact-force guided radiofrequency vs. second-generation balloon cryotherapy for pulmonary vein isolation in patients with paroxysmal atrial fibrillation-a prospective evaluation. Europace 2014; doi:10.1093/europace/euu215.

28. Reddy VY, Sediva L, Petru J, Skoda J, Chovanec M, Chitovova Z, DI Stefano P, Rubin E, Dukkipati S, Neuzil P. Durability of Pulmonary Vein Isolation with Cryoballoon Ablation: Results from the SUstained PV Isolation with ARctic Front Advance (SUPIR) Study. J Cardiovasc Electrophysiol. 2015 Jan 31. doi: 10.1111 /jce.12626

29. Van Belle Y, Michels M, Jordaens L. Focal AF-ablation after Pulmonary Vein Isolation in a Patient with Hypertrophic Cardiomyopathy Using Cryothermal Energy. Pacing Clin Electrophysiol. 2008 Oct;31(10):1358-61.

30. Losi MA, Betocchi S, Aversa M, Lombardi R, Miranda M, D'Alessandro G, Cacace A, Tocchetti CG, Barbati G, Chiariello M. Determinants of atrial fibrillation development in patients with hypertrophic cardiomyopathy. Am J Cardiol. 2004 Oct 1;94(7):895-900. 